\title{
COMPARISON OF HAEMODYNAMIC RESPONSES TO INSERTION OF LARYNGEAL MASK AIRWAY AND ENDOTRACHEAL TUBE
}

\author{
Subhash Ranjan Das ${ }^{1}$, Tushar H. Majumder², Ranjit Reang 3 \\ ${ }^{1}$ Associate Professor, Department of Anaesthesiology, Agartala Government Medical College, Agartala. \\ ${ }^{2} 3^{\text {rd }}$ Year Postgraduate Trainee, Department of Anaesthesiology, Agartala Government Medical College, Agartala. \\ 3 Senior Resident, Department of Anaesthesiology, Agartala Government Medical College, Agartala.
}

ABSTRACT
BACKGROUND
Objectives - Laryngeal mask airway insertion is an alternative method to endotracheal intubation for maintaining airway and
anaesthesia. This study was done to compare the haemodynamic responses associated with laryngeal mask airway insertion and
endotracheal intubation in ASA Grade I patients only undergoing elective surgeries.

\section{MATERIALS AND METHODS}

Between January 2015 and December 2015, study was conducted on fifty adult patients undergoing elective surgery under general anaesthesia in ASA Grade I to compare the haemodynamic responses associated with laryngeal mask airway insertion and endotracheal intubation at Agartala Government Medical College and GBP Hospital. They were divided into two groups of 25 patients each. Group - 1 (Control Group) was endotracheal tube group and Group - II (Study Group) was laryngeal mask airway group.

\section{RESULTS}

The heart rate, systolic and diastolic blood pressure was found to be increased at laryngoscopy and endotracheal intubation or laryngeal mask insertion. But the increase in HR, SBP and DBP in the laryngeal mask airway group was not as much as in the endotracheal tube group. There was a significant difference in these haemodynamic parameters between the two groups at the end of 5 minutes.

\section{CONCLUSION}

The conclusions drawn from this study were that the haemodynamic responses are attenuated and short lived with laryngeal mask airway insertion as compared to laryngoscopy and endotracheal tube intubation. Laryngeal mask airway insertion is quite advantageous wherever there is a concern about the pressor response for airway instrumentation

\section{KEYWORDS}

LMA; Endotracheal Intubation; Haemodynamic Responses.

HOW TO CITE THIS ARTICLE: Das SR, Majumder TH, Reang R. Comparison of haemodynamic responses to insertion of laryngeal mask airway and endotracheal tube. J. Evolution Med. Dent. Sci. 2017;6(23):1867-1871, DOI: 10.14260/Jemds/2017/410

\section{BACKGROUND}

Endotracheal intubation is the translaryngeal placement of endotracheal tube into the trachea via nose (nasotracheal intubation) or mouth (orotracheal intubation). ${ }^{1}$

Laryngeal mask airway insertion is an alternative method to endotracheal intubation for maintaining airway and anaesthesia. ${ }^{2}$ In contrast to endotracheal intubation, laryngeal mask airway insertion does not require instrumentation, i.e. laryngoscopy of the upper airway. ${ }^{3}$ Moreover laryngeal mask airway does not pass through glottis, but is placed over the glottis. ${ }^{4}$

Laryngoscopy and tracheal intubation or laryngeal mask airway insertion are noxious stimuli, which provoke a transient but marked sympathetic response manifesting as hypertension and tachycardia. ${ }^{5}$

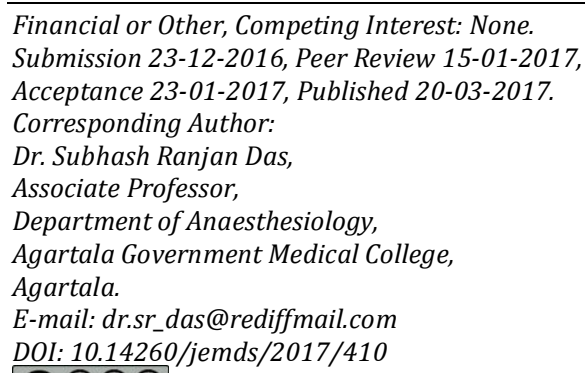

In susceptible patients, particularly those with systemic hypertension, coronary heart disease, cerebrovascular disease and intracranial aneurysm even these transient changes can result potentially deleterious effects, eg: left ventricular failure, arrhythmias, myocardial ischaemia, cerebral haemorrhage and rupture of cerebral aneurysm. ${ }^{6}$

There are many numbers of ways to blunt these haemodynamic changes. They include minimising the duration of laryngoscopy to less than 15 seconds, the use of intravenous narcotics, the use of intravenous lidocaine, vasodilators and beta-blocking agents.

Laryngeal mask airway insertion involves lesser mechanical manipulation of upper airway than endotracheal intubation. ${ }^{8}$ In this study, an effort has been made to compare the haemodynamic response to endotracheal intubation and laryngeal mask airway insertion. ${ }^{9}$

\section{Aim of the Study \\ To compare the haemodynamic responses associated with laryngeal mask airway insertion and endotracheal intubation in ASA Grade I and II patients undergoing elective surgeries.}

\section{MATERIALS AND METHODS}

The study was conducted to compare the cardiovascular response to insertion of laryngeal mask airway to that of tracheal tube intubation on fifty adult patients undergoing elective surgery under general anaesthesia in ASA Grade I. 
Informed consent was obtained in all cases of both sexes and ranged from 20 - 50 years.

The patients were divided into two groups at random (25 patients in each group).

Group I (Control Group) - Endotracheal tube group.

Group II (Study Group) - Laryngeal mask airway group.

The investigation carried out before subjecting the patients for surgery were haemogram, urine analysis, blood chemistry, electrocardiogram and chest $\mathrm{x}$-ray.

\section{Anaesthetic Technique}

After premedication with injection midazolam $0.015 \mathrm{mg} / \mathrm{kg}$, injection glycopyrrolate $10 \mathrm{mcg} / \mathrm{kg}$ and injection pentazocine $0.5 \mathrm{mg} / \mathrm{kg}$ of body weight all the patients were preoxygenated for three minutes. Induction of anaesthesia was done with injection propofol $2 \mathrm{mg} / \mathrm{kg}$ body weight. Intubation was facilitated by using injection succinylcholine $1.5 \mathrm{mg} / \mathrm{kg}$. Patients were ventilated with $100 \%$ oxygen and intubation with the aid of Macintosh laryngoscope or insertion of laryngeal mask airway was carried out. Endotracheal tube or laryngeal mask of appropriate size was used. Time taken for intubation or insertion of laryngeal mask airway did not exceed 20 seconds. Anaesthesia was maintained with intermittent positive pressure ventilation with nitrous oxide and oxygen (66:33) and injection atracurium $(0.5 \mathrm{mg} / \mathrm{kg}$ body weight). Surgery was not allowed to commence till the study was completed, i.e. for five minutes after intubation/insertion.

\section{Monitoring}

Consisted of measuring of -

1. Heart rate.

2. Blood pressure systolic, diastolic and mean arterial pressure using NIBP at different intervals like:

a) Immediate before induction.

b) Immediate after induction.

c) At laryngoscopy and intubation or insertion of laryngeal mask and at 1,3 and at 5 mins.

3. Adequacy of ventilation was monitored clinically.

Mean arterial pressure was calculated by using the formula: $\mathrm{MAP}=$ Diastolic pressure $+1 / 3^{\text {rd }}$ pulse pressure (Where pulse pressure $=$ systolic-diastolic pressure).

Rate pressure product will be calculated by using the formula: RPP = Systolic pressure $\mathrm{X}$ pulse rate.

\section{RESULTS}

From the study conducted the observations were made at following intervals-

1. Pre-induction.

2. After induction.

3. Just after Laryngoscopy and intubation/insertion of laryngeal mask.

4. One minute after intubation/insertion.

5. Three minutes after intubation/insertion.

6. Five minutes after intubation/insertion.

The control group comprises of 17 males and 8 females and study group comprises of 17 males and 8 females. The ages ranged from 20 to 50 years and 21 to 50 years in the control and study groups respectively. The range for weight was 41 to $72 \mathrm{kgs}$ and 52 to $78 \mathrm{~kg}$ in the control and study groups respectively. There was no statistically significant difference. The demographic data was comparable in both the groups.

The haemodynamic parameters in control and study groups recorded during the pre-induction time, i.e. just before pre-oxygenation. There was no significant difference in these readings $(\mathrm{p}>0.05)$. Pre-induction readings are taken as basal value.

\begin{tabular}{|c|c|c|c|}
\hline $\begin{array}{c}\text { Para- } \\
\text { meters }\end{array}$ & Controls & Study & P Value* $^{*}$ \\
\hline HR & $87.20 \pm 6.12$ & $92.08 \pm 9.44$ & 0.0180 \\
\hline SBP & $103.20 \pm 0.23$ & $95.52 \pm 21.49$ & 0.0573 \\
\hline DBP & $74.32 \pm 6.62$ & $69.60 \pm 6.08$ & 0.0058 \\
\hline PP & $28.88 \pm 12.54$ & $25.92 \pm 21.97$ & 0.2810 \\
\hline RPP & $8986.88 \pm 983.99$ & $8785.92 \pm 250.19$ & 0.3425 \\
\hline MAP & $83.95 \pm 5.27$ & $78.24 \pm 8.45$ & 0.0033 \\
\hline Table 1. Haemodynamic Parameters after Induction \\
\hline
\end{tabular}

*Student ' $\mathrm{t}$ ' test.

\section{Tests of Significance were carried out by Student t-test or} Modified t-test

Table showing haemodynamic parameters of both the groups following induction.

In both the groups there was fall in systolic, diastolic and mean arterial pressures. The fall is not significant in the same group as well as between the two groups. A slight increase in the heart rate was observed. It was not statistically significant $(p>0.05)$.

\begin{tabular}{|c|c|c|c|}
\hline $\begin{array}{c}\text { Para-- } \\
\text { meters }\end{array}$ & Controls & Study & P Value* $^{*}$ \\
\hline HR & $113.04 \pm 6.03$ & $109.60 \pm 8.53$ & 0.0531 \\
\hline SBP & $136.56 \pm 9.30$ & $115.28 \pm 10.06$ & 0.0001 \\
\hline DBP & $94.32 \pm 6.82$ & $79.52 \pm 7.35$ & 0.0001 \\
\hline PP & $42.24 \pm 7.00$ & $35.76 \pm 11.93$ & 0.0122 \\
\hline RPP & $15466.08 \pm 1634.58$ & $12645.28 \pm 1568.48$ & 0.0001 \\
\hline MAP & $108.40 \pm 7.00$ & $91.44 \pm 6.18$ & 0.0001 \\
\hline \multicolumn{3}{|c|}{ Table 2. Haemodynamic Parameters at the Time of } \\
Intubation/Insertion of Laryngeal Mask Airway \\
\hline
\end{tabular}

*Student ' $\mathrm{t}$ ' test.

- Values are mean with standard deviation in brackets ( \pm )

- Tests of significance were carried out by student's test or modified t-test.

- $\quad$ Rise was significantly low in the study group, $\mathrm{p}<0.05$.

Table showing the values of haemodynamic parameters at laryngoscopy and intubation/insertion of laryngeal mask. There was rise in all the parameters in both the groups, but the rise was significantly low in the study group $(\mathrm{p}<0.05)$.

\begin{tabular}{|c|c|c|c|}
\hline $\begin{array}{c}\text { Para- } \\
\text { meters }\end{array}$ & Controls & Study & P Value* \\
\hline HR & $112.40 \pm 8.04$ & $106.96 \pm 16.02$ & 0.0690 \\
\hline SBP & $132 \pm 8.20$ & $112.64 \pm 8.67$ & 0.0001 \\
\hline DBP & $93.76 \pm 6.72$ & $78.08 \pm 7.93$ & 0.0001 \\
\hline PP & $38.24 \pm 6.30$ & $34.56 \pm 8.97$ & 0.0503 \\
\hline RPP & $14865.92 \pm 1695.23$ & $11997.68 \pm 1656.80$ & 0.0001 \\
\hline MAP & $106.51 \pm 6.61$ & $89.60 \pm 7.01$ & 0.0001 \\
\hline Table 3. Haemodynamic Parameters One Minute after \\
Intubation/Insertion of Laryngeal Mask Airway \\
\hline
\end{tabular}


*Student ' $t$ ' test.

- Values are mean with standard deviation in brackets $( \pm$ ).

- Tests of significance were carried out by student's t-test or modified t-test.

- $\quad$ Rise was significantly low in the study group $(\mathrm{p}<0.05)$.

Table showing the values of haemodynamic parameters one minute after laryngoscopy and intubation/laryngeal mask insertion. In the control group, all the values were significantly well above the pre-induction values. The parameters in the study group were not significantly increased $(\mathrm{p}<0.05)$.

\begin{tabular}{|c|c|c|c|}
\hline $\begin{array}{c}\text { Para- } \\
\text { meters }\end{array}$ & Controls & Study & P Value* $^{*}$ \\
\hline HR & $107.36 \pm 8.74$ & $98.80 \pm 12.50$ & 0.0038 \\
\hline SBP & $121.52 \pm 8.08$ & $108.16 \pm 11.00$ & 0.0001 \\
\hline DBP & $85.84 \pm 6.43$ & $76.32 \pm 6.37$ & 0.0001 \\
\hline PP & $35.68 \pm 8.49$ & $31.84 \pm 10.47$ & 0.0806 \\
\hline RPP & $13012.56 \pm 944.34$ & $10625.92 \pm 1295.85$ & 0.0001 \\
\hline MAP & $97.73 \pm 5.77$ & $86.93 \pm 6.56$ & 0.0001 \\
\hline \multicolumn{4}{|c|}{ Table 4. Haemodynamic Parameters Three Minutes } \\
after Intubation/Insertion of Laryngeal Mask Airway \\
\hline
\end{tabular}

*Student's ' $t$ ' test

- Values are mean with standard deviation in brackets ( \pm ).

- Tests of significance were carried out by student's t-test or modified t-test.

Table showing haemodynamic parameters of both the groups 3 minutes after intubation/insertion of laryngeal mask airway. The parameters were still high in the control group. The values in study group were nearing the basal values. The difference was statistically significant $(\mathrm{p}<$ $0.05)$.

\begin{tabular}{|c|c|c|c|}
\hline $\begin{array}{c}\text { Para- } \\
\text { meters }\end{array}$ & Controls & Study & P Value* $^{*}$ \\
\hline HR & $95.52 \pm 12.05$ & $92.56 \pm 10.16$ & 0.1762 \\
\hline SBP & $110.24 \pm 8.39$ & $104.08 \pm 8.97$ & 0.0078 \\
\hline DBP & $81.12 \pm 7.00$ & $74.32 \pm 5.12$ & 0.0002 \\
\hline PP & $29.12 \pm 6.51$ & $29.76 \pm 7.19$ & 0.3714 \\
\hline RPP & $10517.44 \pm 1423.85$ & $9633.76 \pm 1350.59$ & 0.0145 \\
\hline MAP & $90.83 \pm 6.84$ & $84.24 \pm 5.73$ & 0.0003 \\
\hline Table 5. Haemodynamic Parameters Five Minutes after \\
Intubation/Insertion of Laryngeal Mask Airway \\
\hline
\end{tabular}

*Student's ' $\mathrm{t}$ ' test

Values are mean with standard deviation in brackets $( \pm)$.

Tests of significance were carried out by the student's ttest or modified t-test Table showing the haemodynamic parameters 5 minutes after intubation insertion. Comparison of parameters in both groups shows that the values were nearing the basal values. There was no statistically significant difference. In our study basal values, i.e. the pre-induction values were assumed as ' $\mathrm{Z}$ ' and the values obtained thereafter were assumed as 'Z-alfa.' From the study, it can be analysed that ' $\mathrm{Z}$ ' is less than 'Z-alfa' in the study group. Thus, we concluded that our study was statistically significant and we rejected null hypothesis, i.e. the haemodynamic parameters were less with laryngeal mask airway insertion at $5 \%$ level of significance.

\begin{tabular}{|c|c|c|c|c|c|c|c|}
\hline Parameters & & HR & SBP & DBP & PP & RPP & MAP \\
\hline \multirow{3}{*}{ Pre- } & $\mathrm{C}$ & $81.28 \pm 10.21$ & $117.52 \pm 11.99$ & $79.52 \pm 8.31$ & $38.00 \pm 9.60$ & $9625.12 \pm 1990.19$ & $92.19 \pm 8.57$ \\
\hline & $\mathrm{S}$ & $82.00 \pm 7.63$ & $111.12 \pm 9.47$ & $79.20 \pm 5.69$ & $31.92 \pm 8.17$ & $9145.44 \pm 1416.84$ & $89.84 \pm 6.05$ \\
\hline & $\mathrm{P}$ & 0.3895 & 0.0209 & 0.4373 & 0.0100 & 0.1658 & 0.1348 \\
\hline \multirow{3}{*}{ After- } & $\mathrm{C}$ & $87.20 \pm 6.12$ & $103.20 \pm 10.23$ & $74.32 \pm 6.62$ & $28.88 \pm 12.54$ & $8986.88 \pm 983.99$ & $83.95 \pm 5.27$ \\
\hline & S & $92.08 \pm 9.44$ & $95.52 \pm 21.49$ & $69.60 \pm 6.08$ & $25.92 \pm 21.97$ & $8785.92 \pm 2250.19$ & $78.24 \pm 8.45$ \\
\hline & $\mathrm{P}$ & 0.0180 & 0.0573 & 0.0058 & 0.2810 & 0.3425 & 0.0033 \\
\hline \multirow{3}{*}{$\begin{array}{c}\text { Insertion } \\
\text { of LMA }\end{array}$} & $\mathrm{C}$ & $113.04 \pm 6.03$ & $136.56 \pm 9.30$ & $94.32 \pm 6.82$ & $42.24 \pm 7.00$ & $15466.08 \pm 1634.58$ & $108.40 \pm 7.00$ \\
\hline & $\mathrm{S}$ & $109.60 \pm 8.53$ & $115.28 \pm 10.06$ & $79.52 \pm 7.35$ & $35.76 \pm 11.93$ & $12645.28 \pm 1568.48$ & $91.44 \pm 6.18$ \\
\hline & $P$ & 0.0535 & 0.0001 & 0.0001 & 0.0122 & 0.0001 & 0.0001 \\
\hline \multirow{3}{*}{1 Minute } & $\mathrm{C}$ & $112.40 \pm 8.04$ & $132 \pm 8.20$ & $93.76 \pm 6.72$ & $38.24 \pm 6.30$ & $14865.92 \pm 1695.23$ & $106.51 \pm 6.61$ \\
\hline & $S$ & $106.96 \pm 16.02$ & $112.64 \pm 8.67$ & $78.08 \pm 7.93$ & $34.56 \pm 8.97$ & $11997.68 \pm 1656.80$ & $89.60 \pm 7.01$ \\
\hline & $\mathrm{P}$ & 0.0690 & 0.0001 & 0.0001 & 0.0503 & 0.0001 & 0.0001 \\
\hline \multirow{3}{*}{3 Minutes } & $\mathrm{C}$ & $107.36 \pm 8.74$ & $121.52 \pm 8.08$ & $85.84 \pm 6.43$ & $35.68 \pm 8.49$ & $13012.56 \pm 944.34$ & $97.73 \pm 5.77$ \\
\hline & $\mathrm{S}$ & $98.80 \pm 12.50$ & $108.16 \pm 11.00$ & $76.32 \pm 6.37$ & $31.84 \pm 10.47$ & $10625.92 \pm 1295.85$ & $86.93 \pm 6.56$ \\
\hline & $\mathrm{P}$ & 0.0038 & 0.0001 & 0.0001 & 0.0806 & 0.0001 & 0.0001 \\
\hline \multirow{3}{*}{5 Minutes } & $\mathrm{C}$ & $95.52 \pm 12.05$ & $110.24 \pm 8.39$ & $81.12 \pm 7.00$ & $29.12 \pm 6.51$ & $10517.44 \pm 1423.85$ & $90.83 \pm 6.84$ \\
\hline & $S$ & $92.56 \pm 10.16$ & $104.08 \pm 8.97$ & $74.32 \pm 5.12$ & $29.76 \pm 7.19$ & $9633.76 \pm 1350.59$ & $84.24 \pm 5.73$ \\
\hline & $\mathrm{P}$ & 0.1762 & 0.0078 & 0.0002 & 0.3714 & 0.0145 & 0.0003 \\
\hline
\end{tabular}

HR: Heart Rate; SBP: Systolic Blood Pressure; DBP: Diastolic Blood Pressure; PP: Pulse Pressure; RPP: Rate Pressure Product; MAP: Mean Arterial Pressure.

\section{DISCUSSION}

Laryngoscopy results in stimulation of pharyngeal wall and causes marked haemodynamic changes (Reid and Brace 1940). Endotracheal tube passes through glottis and causes a continuous stimulus for provocation of haemodynamic response. The pressor response to tracheal intubation may be 
harmful to patients with ischaemic heart disease, hypertension or cerebrovascular disease (Prys-Roberts, Green, Medoche, et al). ${ }^{5}$

Attempts are made to attenuate this response with a variety of pharmacological manoeuvres and more recently effect of fibre optic laryngoscopy was investigated (Smith). ${ }^{10}$ In 1983, Brain ${ }^{11,12}$ described laryngeal mask airway. It does not pass through glottis; rather it sits above the glottis. Moreover, insertion of laryngeal mask airway avoids laryngoscopy.

Stimulation of mechanoreceptors in the pharyngeal wall, epiglottis and vocal cords is thought to be the cause for the haemodynamic response. The receptors are abundant over arytenoid cartilage, vocal cords, epiglottis and hypopharynx.

In our study, we tried to compare the cardiovascular responses to laryngeal mask airway insertion and tracheal intubation. The study was conducted on fifty adult patients. They were divided into two groups, Control group (the Endotracheal tube group) and Study group (the laryngeal mask airway group).

All patients received injection midazolam $0.015 \mathrm{mg} / \mathrm{kg}$ body weight, injection glycopyrrolate $10 \mathrm{mcg} / \mathrm{kg}$ body weight and injection pentazocine $0.5 \mathrm{mg} / \mathrm{kg}$ body weight intravenously 3 minutes prior to induction.

Induction was carried out by injection thiopentone sodium with a dose of $3-5 \mathrm{mg} / \mathrm{kg}$ body weight and intubation or insertion of laryngeal mask airway was facilitated succinylcholine $1 \mathrm{mg} / \mathrm{kg}$.

Heart rate, systolic blood pressure, diastolic blood pressure were recorded at regular intervals, i.e. after induction at the time of laryngoscopy and intubation or insertion of laryngeal mask and 1 min, 3 mins and 5 mins after intubation or laryngeal mask insertion. Both heart rate and blood pressure recordings were made by using a noninvasive blood pressure monitor. (NEC BIOVIEW 1000). The anthropometric data of both groups were comparable. The pre-induction values in both the groups were comparable and there was no statistically significant difference between them $(\mathrm{p}>0.05)$.

Following induction with thiopentone sodium, there was a fall in systolic and diastolic blood pressure and a slight rise in heart rate in both the groups. ${ }^{13}$ However, this was statistically insignificant $(p>0.05)$.

The systolic blood pressure was found to be increased at laryngoscopy and endotracheal intubation or laryngeal mask insertion. But the increase in systolic BP in the study group was not as much as in the control group. It was statistically significant $(\mathrm{p}<0.05)$. The systolic blood pressure after one minute was nearing the basal value in the study group, whereas in the control group it reached its basal value at five minutes $(p>0.05)$. There was a statistically significant difference between the two groups at end of three minutes ( $p$ $<0.05$ ).

Wilson, Fell, Robinson (1940) compared the cardiovascular responses to laryngeal mask airway insertion and endotracheal intubation. They found that mean maximum increase in systolic blood pressure after laryngoscopy and endotracheal intubation was 51.3 percent compared to 22.9 percent for laryngeal mask airway insertion.

In the present study, the diastolic blood pressure at the time of insertion of laryngeal mask airway or endotracheal intubation was increased, but there was a significant increase in control group than study group $(\mathrm{p}<0.05)$. The diastolic blood pressure has reached to basal value after one minute in study group, whereas it took five minutes for control group to achieve basal value. And also, there was a significant difference between these two groups of three minutes $(\mathrm{p}<$ 0.05).

Braude N, Clements E.A.F., Hodges U.M. et al (1989) ${ }^{5}$ conducted a study on pressor response of laryngeal mask airway in comparison with endotracheal intubation. They concluded that there were significant differences between the two groups in arterial diastolic pressure immediately after insertion or intubation and again two minutes after the insertion or intubation.

In our study, mean arterial pressures at the time of insertion of laryngeal mask airway or endotracheal intubation were increased in both the groups in a study. But there was a significant rise in the control group ( $<<0.05)$. The mean arterial pressure in the study group has reached to its basal value at one minute, whereas it took five minutes for the control group to achieve the basal value. And there was a statistically significant difference between the mean arterial pressures of both groups at the end of three minutes, $(\mathrm{p}<$ 0.05).

Barclay K, Wall T, Wareham K et al (1994) ${ }^{14}$ have performed randomised prospective study to examine the effects of tracheal intubation and laryngeal mask insertion. They have concluded that the insertion of laryngeal mask had minimal effects on mean arterial pressure and heart rate, whereas tracheal intubation significantly increased both factors relative to pre-induction values.

In the present study heart rate at the time of insertion of LMA or endotracheal intubation was increased in both groups, but the increase was significant in control group ( $\mathrm{p}<$ 0.05 ). Heart rate reached its basal value within five minutes. But the heart rate was still high in control group after five minutes also. However, the difference was not statistically significant. There was significant difference of heart rate at one minute and three minutes interval between control and study group.

Rate pressure product which is the measure of myocardial oxygen demand is high at all intervals in control group than study group.

Wilson IG, Fell D, Robinson SL (1994) conducted a study on cardiovascular responses to laryngeal mask insertion. They found that there was a greater elevation of heart rate in response to endotracheal intubation than the laryngeal mask airway insertion and remained elevated for a longer period with endotracheal intubation.

Lamb K, James MF, Janicki $1992^{15}$ performed a comparative study on cardiovascular responses to laryngeal mask airway insertion and endotracheal intubation. They have noticed that mean rate pressure was significantly lower in response to laryngeal mask airway insertion when compared to endotracheal intubation after insertion 8276 (730) versus 13307 (1348) ( $\mathrm{p}<0.01)$.

Results of the present study are consistent with the previous studies, in that the haemodynamic response to laryngeal mask insertion is less than to that of endotracheal intubation.

\section{CONCLUSION}

The following Conclusions can be drawn from our Study 
- Pressor response to laryngeal mask airway insertion is much less than that of laryngoscopy and endotracheal intubation.

- Duration of the pressor response is also transient in response to laryngeal mask airway insertion.

- It establishes the usefulness of laryngeal mask airway in airway management during anaesthesia in patients who marked pressor response would be deleterious.

- $\quad$ No untoward incident is seen with airway management by laryngeal mask airway.

\section{REFERENCES}

[1] Stoelting RK, Miller RD. Endotracheal intubation. In: Anesthesia. $1^{\text {st }}$ edn. Churchill Livingstone 1981:233-5.

[2] Benumof JL. Laryngeal mask airway and the ASA difficult airway algorithm. Anesthesiology 1996;84(3):686-99.

[3] Brain A. Proper technique for insertion of the laryngeal mask. Anesthesiology 1990;73(5):1053-4.

[4] Morgan EG. Clinical anaesthesiology. $3^{\text {rd }}$ edn. Lange medical books. Mc Grawn-Hill Medical Publishing Division 2002:p 70.

[5] Roberts PC, Greene LT, Medoche R, et al. Studies of anaesthesia in relation to hypertension. II. Haemodynamic consequences of induction and endotracheal intubation. Br J Anaesth 1971;43(6):53147.

[6] Miller RD. Miller's anaesthesia. $6^{\text {th }}$ edn. Elsevier Churchill Livingstone 2005:p 3203.
[7] Kumar KS. A comparative study of agents for insertion of laryngeal mask airway. Ind J Anaesth 1998;42:27-9.

[8] Pennant JH, Walker MB. Comparison of endotracheal tube and laryngeal mask in airway management by paramedical personnel. Anesth Analg 1992;74(4):5314.

[9] Dorsch JA. Understanding anaesthesia equipment. $4^{\text {th }}$ edn. William and Wilkins 1999:464-87.

[10] Smith JE. Heart rate and arterial pressure changes during fibreoptic tracheal intubation under general anaesthesia. Anaesthesia 1988;43(8):629-32.

[11] Brain AI, Verghese C, Addy EV, et al. The intubating laryngeal mask: development of a new device for intubation of trachea. Br J Anaesth 1997;79(6):699-703.

[12] Brain AIJ, Verghese C, Addy EV, et al. The intubating laryngeal mask: a preliminary clinical report of a new means of intubating the trachea. $\mathrm{Br} \mathrm{J}$ Anaesth 1997;79(6):704-9.

[13] Dyer RA, Llewellyn RL, James MF. Total IV anaesthesia with propofol and laryngeal mask for orthopaedic surgery. Br J Anaesth 1995;74(2):123-8.

[14] Barclay $\mathrm{K}$, Wall $\mathrm{T}$, Wareham $\mathrm{K}$, et al. Intra-ocular pressure changes in patients with glaucoma. Comparison between the laryngeal mask airway and tracheal tube. Anaesthesia 1994;49(2):159-62.

[15] Lamb K, James MF, Janicki PK. The laryngeal mask airway for intraocular surgery: effects on intraocular pressure and stress responses. $\mathrm{Br} J$ Anaesth 1992;69(2):143-7. 